\title{
Tafsir Ayat Hak Anak dan Relevansinya dengan Pendidikan Anak Usia Dini
}

\author{
ITAH MIFTAHUL ULUM \\ Program Studi Akuntansi, Universitas Swadaya Gunung Jati Cirebon \\ Email: kangulum2011@gmail.com
}

\begin{abstract}
The purpose of this research is to know some verses of the Qur'an and the Hadith of the Prophet on the rights of the child and its relevance with the child's education so that it can bring up a concept of early childhood education. Research methods in this study are al-tafsir al-maudhu'i, which starts from the inventory of the verses of the Qur'an and the Prophet's hadith about the rights of the child. The understanding of the verses of the Qur'an and the hadith of the Prophet begins with the approach of interpretation of bi al-mantsur and alqawaid al-'arabiyah, and tafsir bi al-mantsur dan al-qawaid al-'arabiyah, and ilmu tanasub al-suwar wa al-ayat. Then, referring to the commentators 'interpretations and the hadith scholars' hadiths to be analyzed and synthesized. Furthermore, find relevance with the education of children, then designed into a concept of early childhood education. The results of this research, is the rights of the child according to the Islam consists of a good parent has rights, the right to life, the right to health, the right syi'ar Islam, the right intake of nutrition and rights in education. As for the relevance to the child's education, is concerned about the system of values, functions in upbringing, learning materials, and learning methodology. The usefulness of this study is that it contributes to positive about the concept of early childhood education, so that it can serve as a guide in educating children, so that they become children of the noble character and Salih, creating a family of sakinah, and foster a sense of compassion.
\end{abstract}

Keywords: Rights of the children, Child education, Shalih Kids.

\begin{abstract}
Abstrak
Tujuan dari penelitian ini adalah untuk mengetahui ayat-ayat al-Qur'an dan hadits Nabi tentang hak-hak anak dan relevansinya dengan pendidikan anak, sehingga bisa melahirkan sebuah konsep pendidikan anak usia dini. Metodologi penelitian yang digunakan adalah al-tafsir al-maudhu'i, yang dimulai dari menginventarisir ayat alQur'an dan hadits Nabi tentang hak-hak anak. Pemahaman ayat al-Qur'an dan hadits Nabi tersebut, dimulai dengan pendekatan tafsir bi al-mantsur dan al-qawaid al'arabiyah, dan ilmu tanasub al-suwar wa al-ayat. Kemudian, merujuk tafsir para ahli tafsir dan syarh hadits para ahli hadits untuk dianalisis dan disintesis. Selanjutnya, dicarikan relevansinya dengan pendidikan anak, kemudian didesain menjadi sebuah konsep pendidikan anak usia dini. Hasil dari penelitian ini, adalah hak anak menurut Islam terdiri dari hak memiliki orangtua yang baik, hak hidup, hak kesehatan, hak syi'ar Islam, hak asupan bergizi, dan hak pendidikan. Adapun relevansinya dengan pendidikan anak, adalah menyangkut sistem nilai, fungsi pengasuhan, materi pembelajaran, dan metodologi pembelajaran. Kegunaan dari penelitian ini, adalah memberikan kontribusi positif tentang konsep pendidikan anak usia dini, sehingga bisa dijadikan panduan dalam mendidik anak, agar menjadi anak yang shalih dan berakhlak mulia, menciptakan keluarga sakinah, dan menumbuhkan kasih sayang.
\end{abstract}

Kata Kunci: Hak Anak, Pendidikan Anak, Anak Shalih.

\section{Pendahuluan}

Perhatian orangtua terhadap pendidikan anak usia dini mendapat perhatian lebih, karena pendidikan pada anak usia dini ini termasuk pondasi pendidikan. Karena itu, untuk mewujudkan harapan orangtua 
tersebut, al- Qur'an dan Hadits Nabi telah menjelaskan banyak ayat tentang hak-hak anak. Kemudian, di setiap negara di dunia ini, sudah memiliki Undang-undang yang mengatur dan melindungi hak-hak anak.

Pendidikan anak usia dini yang bertujuan melahirkan anak yang baik, memiliki hubungan erat dengan orangtua. Hal demikian, berawal dari persiapan calon suami isteri sebelum menikah, kewajiban berdo'a dan adab sebelum bersetubuh, larangan membunuh janin tanpa alasan yang jelas, hak waris bagi janin, hak diperdengarkan adzan dan iqamah, hak disusui, hak diberi nama yang baik, hak disembelihkan aqiqah, hak dicukurkan rambut, hak untuk dikhitan, hak asuhan dan nafkah, dan hak memperoleh pendidikan.1

Selain itu, terdapat larangan berzina (al-Isra [17]: 32). Menurut al-Sa'di, larangan mendekati zina pada ayat ini termasuk larangan sangat keras, karena di dalamnya termasuk larangan melakukannya. Hukumnya adalah dosa besar yang akan mendatangakan keburukan.2 Juga, terdapat larangan menikah dengan penzina dan orang musyrik (al-Nur [24]: 3). Maksudnya, menikah dengan penzina yang belum bertaubat dan orang musyrik yang belum bertaubat. Orang mukmin yang berzina termasuk orang yang tidak sempurna keimanannya.3

Kedua larangan ini, bertujuan agar orangtua bisa mendapatkan keturunan anak yang baik. Pada umumnya, anak hasil dari perzinahan cenderung mengalami perkembangan kepribadian yang buruk, karena orangtua yang kurang melindungi anaknya, dan perlakuan buruk dari teman sebaya terhadap anak dari hasil perzinahan. Adapun larangan menikah dengan orang musyrik, karena tidak ada keselarasan antara orangtua di dalam pendidikan, dan akan mempersulit keberhasilan pendidikan anak.

Anak hasil dari perzinahan hanya mendapat pengakuan perdata, yaitu hubungan nasab anak jatuh ke pihak Ibunya dan keluarganya, tidak kepada Bapaknya.4 Sebab itu, dampak negatif bagi anak hasil perzinahan adalah sulit mendapatkan suasana yang baik dalam kehidupan keluarga,

1 Wafi, Ali Abdul Wahid, Huquq al-Insan fi alIslam, (Kairo, Dar al-Nahdhah Mishr li al-Thab'i wa al-Nashr, 1979), 56.

2 Al-Sa'di, Abdurahman bin Nashir, Taisir al-Karim alRahman fi Tafsir Kalam al-Manan, (Berut: Muasasah alRisalah, 2000), jld. 1, 457.

3 Al-Sa'di, Taisir al-Karim al-Rahman ......., jld. 1, 561.

4 Pasal 43 UU Republik Indonesia Nomor 1 Tahun 1974 tentang Perkawinan. terutama kasih sayang dari Bapaknya. Walaupun anak yang baru lahir itu suci, namun di dalam kehidupan sehari-hari, anak hasil dari perzinahan kerap mendapatkan ketidak adilan dari orangtuanya, karena tidak ada tanggung jawab, sebagai dampak psikis dari perbuatan dosa kedua orangtuanya.

Walaupun al-Qur'an dan hadits Nabi serta Undang-undang tentang hak-hak anak dengan tegas melindungi hak-hak setiap anak. Namun, sampai saat ini masih banyak pelanggaran terhadap hak-hak anak. Sebab itu, pada tulisan ini, akan dikaji hak-hak anak menurut Islam, yang sebelumnya akan diulas secara sepintas hak-hak anak pada masa jahiliyah, sebagai perbandingan bagaimana gambaran Islam di dalam memuliakan anakanak, yang merupakan amanah dari Allah kepada setiap orangtua.

\section{B. Metodologi Penelitian}

Metodologi penelitian yang digunakan adalah al-tafsir al-maudhu'i, yang dimulai dari menginventarisir ayat al-Qur'an dan hadits Nabi tentang hak-hak anak. Pemahaman ayat al-Qur'an dan hadits Nabi tersebut, dimulai dengan pendekatan tafsir bi al-mantsur dan al-qawaid al -'arabiyah, dan ilmu tanasub alsuwar wa al-ayat. Kemudian, merujuk tafsir para ahli tafsir dan syarh hadits para ahli hadits untuk dianalisis dan disintesis. Selanjutnya, dicarikan relevansinya dengan pendidikan anak, kemudian didesain menjadi sebuah konsep pendidikan anak usia dini.

\section{Pembahasan}

Secara etimologi, di dalam bahasa Arab hak berarti benar atau kebalikan dari bohong.5 Sedangkan secara terminologi, hak (anak) adalah sesuatu yang harus diterima oleh anak, yang berhubungan dengan kebutuhan anak, seperti kebutuhan tubuh, akal, dan hati, yaitu pada saat anak masih janin, sedang menyusui, dan ketika sudah berusia balita, karena anak belum bisa memenuhi kebutuhannya sendiri, tanpa bantuan orangtua yang mengurusnya. 6

Menurut Prints, hak anak adalah pemenuhan kebutuhan anak agar hidup, tumbuh dan berkembang secara manusiawi, serta melindunginya dari segala bentuk kekerasan dan diskriminasi, sehingga menjadi

5 Al-Jurjani, Ali bin Muhammad bin Ali, Al-Ta'rifat, (Berut: Dar al-Kitab al-Arabi, 1405), 120.

6 Nurul Islam, Muhammad Mafhum Huquq alThifli, ((Berut: Dar Ibn Katsir, 2012), 16. 
anak yang baik, berakhlak mulia, dan hidup sejahtera.7

Bila ditinjau dari aspek hukum, hak anak adalah perlindungan negara kepada anak dari dampak buruk peperangan, dan perlindungan hak sipil seperti hak untuk memperoleh akta kelahiran. Pada umumnya, hak-hak anak ini dapat dikelompokan kepada perlindungan fisik, akal, jiwa, dan hak hidup bermasyarakat.8

\section{(1) Hak Anak dalam Islam}

Di dalam tradisi bangsa Arab jahiliyah, bila seorang Ibu dikaruniai anak perempuan, mukanya menghitam pertanda marah (al-Nahl [16]: 58). Menurut al-Baghwi, ketika seorang Ibu melahirkan anak perempuan, dia merasa sedih, dan merahasiakan kelahirkan anak.9 Bayi perempuan dikubur hidup-hidup, dijual, atau digadaikan karena sebab tertentu.10 Menurut Khalil,11 pada masa jahiliyah, hak hidup anak ditentukan oleh kekuatan fisiknya. Pada saat anak baru lahir, seorang anak dimandikan di air sungai, jika tubuh anak itu kuat, maka anak memperoleh hak hidup. Sebaliknya, bila tubuh anak itu lemah, maka bagi orangtua berhak untuk membunuhnya.

Pada saat kondisi seperti demikian, Islam lahir di negeri Arab untuk mengangkat dan membela kehormatan anak. Perhatian Islam terhadap anak, dibuktikan dengan banyak ayat al -Qur'an dan hadits Nabi tentang hak-hak anak. Adapun hak-hak anak secara lebih terperinci, diatur di dalam alQur'an dan hadits Nabi seperti berikut.

\section{(a) Hak Memilki Orangtua yang Baik}

Sebelum anak lahir, ajaran Islam sudah memiliki visi yang jauh untuk memikirkan masa depan anak. Visi tersebut adalah mempersiapkan calon orangtua dengan empat persyaratan, yaitu beragama, keturunan terhormat, kecantikan, dan kekayaan.12

7 Prints, Darwan, Hukum Anak Indonesia, (Bandung: PT. Citra Aditya Bakti, Bandung, 2003), 146.

8 Habib, Mushtafa Rahim Zhahir, Huquq al-Thifli Baina al-Syari'ah wa al-Qanun, (Riyadh: Wizarah al-Ta'lim alAli wa al-Bahts, 2010), 444.

9 Ibnu Mas'ud, Muhyi al-Sunnah Abu Muhammad, Ma'alim al-Tanzil, (Riyadh: Dar Thayyibah li alNasyr wa al-Tauz'i, 1997), jld. 5, 24.

10 Shadiq, Hisyam Ali, Tarikh al-Nuzhum alQanuniyah wa al-Ijtima'iyah (Kairo: Matba'ah Jami'ah al-Qahirah. 1986), 179.

11 Khalil, Ghassan, Huquq al-Thifli, (Berut: Dar Ibn Katrsir, 2001), 24.

12 Al-Bukhari, Muhammad bin Ismail Abu Abdillah, al-Jami al-Shahih, (Berut: Dar Ibn Katsir, 1987),
Namun, Rasulullah menekankan agama sebagai persyaratan primer. Keturunan terhormat, kecantikan, dan kekayaan adalah persyaratan pelengkap.

\section{(b) Hak Hidup}

Hak anak berikutnya, agar menjaga kelangsungan hidup janin, dengan tidak menggugurkan kandungan ketika janin sudah bernyawa (al-Isra [17]: 33). Menurut Abul Abbas, hukum menggugurkan janin yang sudah bernyawa adalah haram.13 Bagi orang yang menggugurkannya tanpa alasan yang jelas, termasuk perbuatan sesat (alAn'am [6]: 140). Menurut al-Thantawi,14 perbuatan dosa ini telah menjadikan pembunuh merugi di dunia dan di Akhirat, dan termasuk pendusta agama.

Hak hidup ini juga bertujuan agar anak tumbuh sehat secara fisik dan psikis, di lingkungan keluarga dan masyarakat tanpa rasa khawatir.15 Hak perlindungan terhadap anak, berlaku juga pada saat peperangan (alBaqarah [2]: 190). Pelanggaran terhadap hak hidup dalam pengertian ini, bisa membenuh karakter anak menjadi anak yang kurang berkepribadian. Karena, hak hidup seperti ini erat kaitannya dengan pendidikan yang harus diterima oleh setiap anak.

\section{(c) Hak Kesehatan Fisik dan Psikis}

Larangan membunuh janin dan bayi di atas, ditindak lanjuti dengan kewajiban menjaga kesehatan janin, dengan mengkonsumsi makanan yang dibutuhkan. Bagi Ibu yang sedang mengandung janin dan sedang berpuasa Ramadhan, diperbolehkan berbuka puasa dengan kewajiban mengqadha di bulan lain.

Selain itu juga, Rasulullah memerintah kepada setiap suami agar menjaga psikis dan perasaan isterinya yang mudah tersinggung, 16 dan agar tetap bersabar menghadapi isteri (al-Nisa [4]; 19), karena akan berdampak kepada kesehatan mental janin.

jld 5, 1958.

13 Abul Abbas, Syamsudin Muhammad, Nihayatul Muhtaj ila Syarhil Minhaj, (Beirut: Dar al-Fikr, 1984), jld 4, 416.

14 Thanthawi, Muhammad Sayyid, al-Tafsir alWasith li al-Qur'an al-Karim, (Kairo: Mathba'ah al-Sa'adah, 1987), 209.

15 Khalil, Huquq al-Thifli ......., 34.

16 AlBukhari, al-Jami al-Shahih, ........ jld 5, 2281. 


\section{(d) Hak Syi'ar Islam}

Hak anak (bayi) yang baru lahir adalah diperdengarkan adzan dan iqamah. Kemudian, dilakukan aqiqah yaitu menyembelih dua ekor hewan qurban bagi anak laki-laki, dan satu ekor hewan qurban bagi anak perempuan, pada hari ketujuh dari kelahiran anak. Hewan qurban yang disembelih, penyembelih, dan peralatan untuk menyembelih harus sesuai dengan yang disyariatkan Allah.17 Hewan yang disembelih diperlakukan dengan baik.18 Kemudian mencukur rambut, dan rambut yang dicukur ditimbang, dan bersedekah seharga perak, seberat rambut yang dicukur.19

Bagi anak yang baru lahir berhak memperoleh nama yang baik. Karena, nama anak akan dipanggil sejak lahir sampai meninggal dunia, dan akan dipanggil oleh Allah pada Hari Kiamat.20 Pemberian nama yang baik termasuk adab dan do'a agar anak memiliki akhlak yang baik. Pemberian nama anak bersambung kepada nasab Bapaknya (al-Ahzab [33]: 5). Pada saat itu disunnahkan untuk dikhitan. Tujuan dari ibadah ini, adalah syi'ar Islam menyambut kehadiran anak, dan ungkapan rasa syukur kepada Allah atas nikmat yang telah diberikan kepada orangtua dari anak yang baru lahir.

\section{(e) Hak Asupan Bergizi}

Asupan bergizi setelah anak lahir adalah air susu ibu selama dua tahun (alBaqarah [2]: 233). Hak anak untuk menyusu ini mendapat perhatian penuh. Allah SWT membolehkan Ibu yang sedang menyusui untuk berbuka puasa di bulan Ramadhan. Bila Ibu tidak bisa menyusui anaknya karena alasan kesehatan, hak anak untuk menyusu dari Ibu kandungnya, boleh disusui oleh perempuan lain (alThalaq [65]: 6). Begitu pula, hak anak utuk menyusu dari Ibu kandungnya yang berzina, maka hukuman bagi Ibu yang berzina bisa ditangguhkan sampai anak berusia dua tahun, disapih oleh Ibunya.21

17 Ali Ghufron, Tuntutan Berqurban dan Menyembelih Hewan Qurban, (Jakarta: Amzah, 2013), 109.

18 Al-Asy'ats, Abu Daud Sulaiman, (Berut: Dar alKitab al-Arabi, 1426), jld 4, 442.

19 Al-Tirmidzi, Muhammad bin Isa Abu Isa, (Berut: Dar Ihya al-Turats al-Arabi, 1427), jld 4, 99.

20 Al-Asy'ats, Sunan Abi Daud, ...., jld 3, 58.

21 Muslim, Abu al-Husain Muslim bin al-Hajjaj, al-Jami al-Shahih, (Berut: Dar al-Jil, 1430), jld 5, 120.

\section{(f) Hak Pendidikan}

Islam sangat memperhatikan hak anak di dalam pendidikan (al-Tahrim [66]: 6). Menurut Ali bin Abi Thalib, ayat ini adalah perintah untuk mendidik, mengajarkan akhlak kepada keluarga. Menurut Ibnu Abbas, maksud dari ayat ini adalah perintah untuk mentaati perintah Allah dan menjauhi larangan-Nya, dan perintah untuk selalu ingat kepada Allah yang bisa menyelamatkan keluarga dari api neraka.22

Hak pendidikan tersebut harus ditanamkan kepada anak sejak kecil, sehingga bisa membekas dan terbawa sampai usia dewasa. Karena itu, setiap kita adalah pemimpin dan memiliki tanggung jawab atas yang dipimpinnya. Seorang Ayah adalah pemimpin rumah tangga dan memiliki tanggung jawab atas yang dipimpinnya, dan seorang Ibu adalah pemimpin bagi anak-anaknya dan memiliki tanggung jawab atas yang dipimpinnya.23

Anak adalah amanah dari Allah bagi orangtua, dan orangtua akan diminta pertanggung jawaban kelak di Akhirat. Kewajiban orangtua bagi anaknya, di antaranya adalah mengajarkan menulis, berenang, memanah, dan memberi rezeki yang baik.24

Sebab itu, pembiasaan akhlak baik harus ditanamkan kepada anak sejak kecil. Kepribadian anak sangat ditentukan oleh peranan orangtua. Pembiasaan bagi anak yang dicontohkan oleh Rasulullah SAW, adalah mengerjakan shalat pada saat anak berusia tujuh tahun, memberi sanksi kepada anak yang sudah berusia sepuluh tahun bila meninggalkan shalat, dan memisahkannya dari tempat tidur.25 Jadi, bisa disimpulkan bahwa Islam mengajarkan pendidikan dan pembiasaan akhlak baik bagi anak secara bertahap dalam materi dan metode pembelajaran.

Selain itu, Rasulullah SAW mengajarkan juga kepada orangtua untuk menafkahi anak dari sumber yang halal, mengajarkan adab makan dan minum, menjaga kesehatan, berolah raga, menanamkan kasih sayang,

22 Al-Thabari, Muhammad bin Jarir, Jamiul Bayan fi Ta'wilil Qur'an, (Berut: Muasasah al-Risalah, 1420), jld 23, 491.

23 Al-Bukhari, al-Jami al-Shahih, ........ jld 5, 1988.

24 Al-Baihaqi, Abu Bakr Ahmad bin al-Husain, alSunan al-Kubro wa fi Dzillati al-Jauhar (Hayderabad India: Majelis Dairah al-Ma'arif alNizhamiyah al-Kainah, 1344), jld 10, 15.

25 Al-Sijistani, Sunan Abi Daud, ...., Jld 1, 185. 
tidak membebani anak, disiplin, dan menanamkan keberanian. Dengan demikian, anak akan memiliki kepribadian yang utuh, disiplin, dan penuh percaya diri, sehingga dapat menjalankan tugas dan kewajibannya.

\section{(e) Hak Perlindungan}

Allah tidak membeda-bedakan antara anak laki-laki dan perempuan (Ali Imran [3]: 195). Artinya, terdapat kesetaraan antara anak laki-laki dan perempuan di dalam beramal shalih. Pembeda antara anak laki-laki dan perempuan terletak di dalam ketakwaan (al-Hujurat [49]: 13). Dari ayat ini, bisa dipahami bahwa Allah telah mendorong orangtua untuk melindungi anak dan melarang untuk berbuat zhalim.

Menurut al-Mawardi,26 Ibnu Abbas, telah menjelaskan bahwa Allah memerintahkan untuk memerangi orang-orang musyrik yang memerangi umat Islam, dan memerintahkan melindungi wanita dan anak-anak. Bahkan, Rasulullah memberikan penghormatan kepada anak perempuan dengan ungkapan khairu auladikum al-banat, sebaik-baiknya anak adalah perempuan. Para sahabat bersepakat untuk tidak membunuh wanita, orang tua, dan anak-anak pada saat terjadi peperangan. 27

\section{(2) Pendidikan Anak Usia Dini}

Berpijak kepada hak - hak anak berdasarkan al-Qur'an dan hadits Nabi di atas, bisa dianalisis dan dirumuskan sebuah konsep pendidikan anak usia dini, sebagai berikut:

\section{(a) Sistem Nilai}

Di dalam pendidikan Islam, khususnya pendidikan anak usia dini berbeda dengan pendidikan remaja atau pendidikan orang dewasa. Faktor pembeda antara ketiga pendidikan ini, adalah pendidikan anak usia ini memiliki ketergantungan yang kuat terutama dengan orangtua. Karena, anak usia dini belum mandiri, terutama kondisi psikis anak dipengaruhi oleh kondisi psikis orangtua.

26 Al-Mawardi, Abul Hasan Ali bin Habib, Tafsir alMawardi, (Kuwait: Mathabi al-Maqhawi, 1982), jld. 4, 210.

27 Abdul Baqi, Abu Abdillah Muhammad, Syarh Muwatha Malik (Kairo: Syirkah wa Maktabah wa Mathba'ah al-Babi al-Halbi wa Auladuhu, 1961), jld. 3, 290.
Pada pembahasan di muka, telah dijelaskan bahwa persiapan untuk melahirkan anak didik yang baik, harus dimulai dari persiapan calon orangtua di dalam berumah tangga. Bagi orangtua yang memiliki karakter baik atau buruk, atau bermasalah secara syar'i seperti berumah tangga karena sebab perzinahan akan mempengaruhi kepribadian anak. Menurut Barnadib,28 yang merujuk kepada pepatah Jawa, yaitu bibit, bebet, dan bobot orangtua akan berpengaruh kepada anak.

Pendidikan anak usia dini yang bersumber kepada al- Qur'an dan hadits Nabi, tidak bisa lepas dari hukum lima, yaitu wajib, sunnah, mubah, makruh dan haram. Perbuatan orang tua yang sesuai atau tidak sesuai dengan hukum lima, akan berdampak kepada anak didik. Hukum lima ini membentuk sistem nilai kultural, sosial, psikologis, dan tingkah laku.29

\section{(b) Kriteria Guru}

Keberhasilan pendidikan anak usia dini, lebih banyak ditentukan oleh kemampuan guru di dalam mendidik. Karena itu, terdapat kriteria yang harus dimiliki oleh guru, yaitu lemah lembut. Pada saat Rasulullah sedang shalat, beliau sempat menggendong cucunya, yaitu Umamah, anak dari Zainab binti Muhammad SAW. Saat beliau sujud, Umamah diletakan di samping beliau, dan pada saat bangkit untuk shalat di rakaat berikutnya, Umamah digendong kembali.30

Memperhatikan sikap Rasulullah tersebut, menunjukan perhatian beliau sangat penyayang. Kasih sayang beliau kepada cucunya tidak disepelekan, sementara beliau sedang mengerjakan shalat. Di sinilah terdapat keseimbangan antara kasih sayang kepada Allah dengan kasih sayang kepada hamba-Nya. Karena, barang siapa tidak menyayangi sesama, tidak akan disayang Allah.31

Jadi, kasih sayang orangtua dan guru kepada anak didiknya, harus diperlihatkan kepada anak, sehingga anak merasakan kehadiran orangtua dan gurunya. Orangtua dan guru yang baik adalah mereka yang memiliki kemampuan untuk masuk ke dunia

\footnotetext{
28 Barnadib, Sutari Imam, Pengantar IImu Pendidikan Sistematis, (Yogyakarta: Andi Offset, 1995), 27.

29 Arifin, Muzayin, Filsafat Pendidikan Islam, (Jakarta: PT Bumi Aksara, 2003), 127.

30 Muslim, al-Jami al-Shahih, ......., jld 2, 73.

31 Al-Bukhari, al-Jami al-Shahih, ......... jld 5, 2235.
} 
anak.

Sementara itu, guru yang baik adalah guru yang memerankan fungsi pengasuhan dan peranan orangtua di rumah. Menurut Mushthafa, 32 pada mulanya istilah pengasuhan diambil dari istilah hadhanah, yaitu pendidikan bagi anak usia dini yang dilakukan seorang perempuan yang menggantikan Ibunya yang sudah meninggal dunia. Pengertian hadhanah secara lebih luas, berarti pendidikan bagi anak kecil, dan pada saat ini fungsi hadhanah bisa dilakukan di sekolah.

Menurut al-Qahthani, hadhanah berarti fungsi pengasuhan dari seorang guru bagi anak didiknya, khususnya menyangkut pendidikan, kesehatan mental, dan pemberian nafkah.33 Pada dasarnya, orang yang wajib menafkahi anak adalah Ayahnya. Namun, bilamana Ayahnya tidak mampu, kewajiban menafkahi anak beralih kepada saudaranya. Menurut al-Kailani, 34 bahwa Imam Syafi'i telah mewajibkan penyelenggara negara untuk memberi kesempatan belajar kepada anak dari keluarga yang tidak mampu.

\section{(c) Materi Pembelajaran}

Pendidikan yang pertama kali harus ditanamkan kepada anak didik adalah pendidikan keimanan. Pada pembahasan di muka, pendidikan keimanan sudah ada sejak anak baru lahir, yaitu diperdengarkan adzan dan iqamah. Kemudian, ketika anak sudah memasuki persiapan usia belajar harus ditanamkan nilainilai tauhid (Ali Imran [3]: 18). Di dalam tafsir al-Baghwi,35 Ibnu Abbas telah menjelaskan, bahwa Allah SWT telah menciptakan ruh dan menetapkan rezeki setiap manusia sejak empat ribu tahun sebelum diciptakan jasad. Pendidikan keimanan, akan mudah diterapkan pada setiap anak didik, bila pendidikan ini ditanamkan sejak kecil, karena hal ini termasuk fitrah dari Allah kepada setiap manusia.

Adapun materi pembelajaran setelah keimanan, yaitu pendidikan akhlak, pendidikan jasmani, pendidikan kecerdasan intelektual, pendidikan kecerdasan emosional, dan

32 Mushthafa, Ibrahim, al-Mu'jam al-Wasith (Kairo: Dar al-Da'wah, 1987), jld 1, 182.

33 Al-Qahthani, Said bin Ali bin Wahf, al-Hadyu alNabawi fi Tarbiyah al-Aulad fi Dhaui al-Kitab wa al-Sunnah, (Riyadh: Muasasah al-Risalah, 2011), 111.

34 Al-Kailani, Majid Irsan, Tarhawwur Mafhum alNazhariyah al-Tarbawiyah al-Islamiyah, (Madinah: Maktabah Dar al-Turats, 1985), 93.

35 Al-Baghwi, Ma'alim al-Tanzil ........, jld. 2, 18. pendidikan kecerdasan sosial.36 Menurut AlHaqil, pendidikan akhlak adalah sekumpulan pedoman berakhlak mulia, keutamaannya, dan keberadaannya yang harus dilalui oleh setiap anak didik, yang dibiasakan sejak kecil sampai mumayyiz dan mukallaf, secara bertahap dalam setiap aspek kehidupan.37 Pendidikan keimanan dan pendidikan akhlak merupakan satu kesatuan yang tidak bisa dipisahkan, karena akhlak adalah hikmah dari pelaksanaan syari'ah yang berdasarkan keimanan.

Di dalam pembahasan di muka, telah dijelaskan hak anak yang baru lahir yang berhubungan dengan jasmani adalah mencukur rambut dan khitan. Menurut AlHaqil, pendidikan jasmani, adalah memberikan hak tubuh agar tetap sehat dan kuat, dan mengendalikan anggota tubuh agar tidak melakukan perbuatan yang bisa merugikan tubuh itu sendiri.38 Karena itu, kurikulum harus memperhatikan keseimbangan pemenuhan hak tubuh dan kewajiban sehari-hari sebagai anak didik.39

Adapun pendidikan intelektual, adalah usaha untuk menumbuh kembangkan pemikiran melalui kegiatan yang bermanfaat, sehingga bisa membentuk anak yang cerdas sesuai syariat Islam.40 Pendidikan ini, bisa dimulai dari perintah bergaul dengan orang yang baik. Rasulullah SAW telah mengilustrasikan orang yang berteman dengan penjual minyak wangi akan mendapatkan wewangian; dan orang yang berteman dengan tukang pandai besi, akan menjadikan pakaian terbakar dan mencium bau yang tidak sedap.41 Sementara itu, pendidikan kecerdasan emosional contohnya mengendalikan amarah dan perasaan takut; dan pendidikan sosial contohnya kasih sayang dan pemaaf.

\section{(d) Metodologi Pembelajaran}

Metodologi pembelajaran yang efektif di dalam mendidik anak usia dini adalah suri tauladan (qudwah hasanah). Rasulullah SAW adalah teladan bagi kita. Pada prinsipnya, suri tauladan adalah mendidik anak melalui

36 Al-Qahthani, Al-Hadyu al-Nabawi ......, 130-131.

37 Al-Haqil, Sulaiman bin Abdurrahman, al-Tarbiyah al-Islamiyah, (Riyadh: Wizaratul 'llam, 1996), 49.

38 Al-Haqil, al-Tarbiyah al-Islamiyah......., 42.

39 Al-Bukhari, al-Jami al-Shahih, .......... jld 2, 697.

40 Ulwan, Abdullah Nasih, Tarbiyatul Aulad fi alIslam, (Jedah: Dar Hafizh li al-Nasyr wa ak-Tauzi, 1400), jld. 1, 255.

41 Al-Bukhari, al-Jami al-Shahih, ......... jld 2, 741. 
cara meniru. Adapun metode pembelajaran yang menunjukan suri tauladan, di antaranya zuhud, tawadhu, ramah, penyayang, tidak mudah marah, dan pemberani. Selain itu, terdapat metode lain yaitu memberi nasihat yang baik, bimbingan, dan sanksi yang tidak memberatkan.42 Metode lain yang di dalam pembelajaran bagi anak usia dini, adalah metode kisah (cerita) dan pembiasaan.43

\section{(e) Urgensi Pendidikan Anak Usia Dini}

Berdasarkan uraian di muka, pendidikan anak usia dini seperti yang dicontohkan oleh Rasulullah SAW, akan mendatangkan hikmah yang menunjukan urgensi pendidikan anak usia dini, yaitu berbuat baik kepada orangtua, melahirkan anak yang shalih, menumbuhkan akhlak terpuji, menciptakan keluarga sakinah, dan menumbuhkan kasih sayang.

Anak yang berbuat baik kepada orangtua adalah cerminan dari keberhasilan orangtua dan guru di dalam mendidik anak. Anak yang berbuat baik kepada orangtua dan guru, tidak semata-mata hasil dari proses pembelajaran, melainkan hikmah dari ketaatan orangtua dan guru kepada Allah di dalam beribadah kepada-Nya (al-Isra [17]: 23-24). Di dalam tafsir al-Sa'di, dijelaskan perbuatan baik anak kepada orangtuanya adalah merupakan hasil dari pendidikan orangtua dan guru, ketika anak masih kecil.44 Bagi guru yang mendidik anak dengan benar akan mendatangkan pahala jariah. 45

Pendidikan yang benar yang berdasarkan ajaran Islam, tidak akan melahirkan anak berkepribadian buruk seperti anak yang menyerupai perempuan dan sebaliknya.46 Anak didik yang demikian, termasuk orang yang berakhlak baik, dan merupakan hasil dari proses pendidikan yang baik pula (al-Qalam [68]: 4). Di dalam tafsir al-Baghyi, dijelaskan bahwa yang dimaksud akhlak mulia di sini, adalah kepribadian Rasulullah yang tercermin dari ajaran alQur'an.47 Pendidikan anak yang seperti ini, akan menumbuhkan kasih sayang di antara orangtua, guru, dan sesama.48

\footnotetext{
42 Al-Qahthani, Al-Hadyu al-Nabawi ......, 131-132.

43 Al-Haqil, al-Tarbiyah al-Islamiyah......, 61-64.

44 Al-Sa'di, Taisir al-Karim al-Rahman ......., jld. 1, 456.

45 Al-Naisaburi, al-Jami al-Shahih, ......., , jld. 5, 73.

46 Al-Bukhari, al-Jami al-Shahih, .......... jld. 5, 2207.

47 Al-Baghwi, Ma'alim al-Tanzil ........, jld. 8, 187.

48 Al-Bukhari, al-Jami al-Shahih, ......... jld. 1, 16.
}

\section{(f) Profil Pendidik}

Berikut ini adalah profil pendidik yang telah diabadikan al-Qur'an, yang bisa dijadikan rujukan dari pembelajaran dan pendidikan bagi anak dengan konsep seperti yang telah dijelaskan di muka.

Nuh AS adalah salah seorang profil pendidik yang baik. Pada saat beliau dan umatnya akan naik perahu karena akan datang musibah banjir, beliau memanggil anaknya Kan'an yang berjauhan tempat agar anaknya naik perahu, dan Nuh AS tetap berdo'a kepada Allah agar diberikan keselamatan bagi anaknya.49 Hal ini menunjukan bahwa sikap orangtua dan guru di dalam mendidik anak, harus memiliki sikap penuh kasih sayang dan berusaha semaksimal mungkin untuk mengarahkan anak didik menjadi orang yang baik.

Ibrahim AS adalah profil lain di dalam pendidikan. Beliau pada saat membangun Ka'bah, bekerja sama dengan anaknya. Beliau berdo'a kepada Allah agar anaknya menjadi seorang pemimpin. Do'a beliau dikabulkan oleh Allah, dan Dia menjelaskan bahwa kepemimpinan Islam tidak akan diberikan kepada orang yang zhalim. Kasus ini, memberi informasi kepada orangtua dan guru, agar anak didik bisa menjadi baik, syaratnya adalah seorang guru harus menjauhi larangan Allah dan ikhlas karena Allah semata. Keberhasilan Ibrahim AS di dalam mendidik anaknya, adalah karena beliau telah mengajarakan kesabaran kepada anaknya Ismail AS.50

Ibrahim juga termasuk seorang Nabi kekasih Allah yang diberi keturunan orang yang baik. Di samping Ibrahim AS memiliki anak yang bernama Ismail AS dan Ishak AS, beliau juga diberi keturunan anak yang shalih, yaitu Ya'qub AS yang termasuk juga seorang profil pendidik yang baik. Sikap Ya'qub AS yang diabadikan al-Qur'an, bahwa beliau tetap mengajarkan untuk beribadah kepada anak-anaknya tanpa henti, sampai ajal akan menjemputnya.51

Sebagaimana Nabi yang lain, Zakaria AS termasuk profil pendidik yang baik pula. Beliau memiliki anak yang baik dan termasuk Nabi pula, yaitu Yahya AS. Keberhasilan Zakaria AS memiliki anak yang shalih, tidak semata-mata metodologi pembelajaran yang dikuasainya, melainkan beliau selalu

49 Al-Sa'di, Taisir al-Karim al-Rahman ......., jld. 1, 382.

50 Al-Baghwi, Ma'alim al-Tanzil ........., jld. 1, 153.

51 Al-Baghwi, Ma'alim al-Tanzil ........., jld. 1, 154. 
mendo'akan anaknya, agar menjadi anak yang shalih, berakhlak baik, dan bermanfaat untuk kehidupan dunia dan Akhirat. 52

Muhammad AS adalah pendidik yang baik berhasil mendidik anak-anaknya dan umatnya, karena beliau sebelum memerintahkan kepada orang lain, beliau sendiri yang memberi contoh yang baik. Di dalam al-Qur'an, Allah SWT memuji beliau dengan akhlak yang agung. Di antara ajaran yang diberikan Muhammad AS kepada anakanaknya dan kepada umatnya adalah perintah shalat. 53 Kepripadian beliau di dalam mendidik anak telah dijelaskan di pembahasan di muka.

\section{Simpulan}

Keberhasilan pendidikan anak sangat dipengaruhi oleh kepribadian orangtua dan guru. Islam memandang faktor genetik dan pengalaman belajar termasuk faktor penentu keberhasilan pendidikan. Keberhasilan pendidikan ini, ditentukan oleh pemenuhan hak-hak anak, yaitu hak memiliki orangtua yang baik, hak hidup, hak kesehatan fisik dan psikis, hak syi'ar Islam, hak asupan bergizi, dan hak pendidikan.

Relevansi tafsir ayat hak anak terhadap pendidikan anak usia dini, adalah menyangkut sistem nilai, fungsi pengasuhan, materi pembelajaran, dan metodologi pembelajaran. Adapun hikmah dari pendidikan anak, yaitu akan melahirkan anak yang shalih dan berakhlak mulia, menciptakan keluarga sakinah, dan menumbuhkan kasih sayang.

\section{E. Daftar Pustaka}

Al-Thabari, Muhammad bin Jarir. (1420). Jam'iul Bayan fi Ta'wilil Qur'an, jld. 23, Berut: Muasasah al-Risalah.

Arifin, Muzayin. (2003). Filsafat Pendidikan Islam, (akarta: PT Bumi Aksara, 2003.

Al-Baihaqi, Abu Bakr Ahmad bin al-Husain. (1344). Al-Sunan Al-Kubro wa fi Dzillati alJauhar, jld. 10, Hayderabad India: Majelis Dairah al-Ma'arif al-Nizhamiyah al-Kainah.

Ibnu Mas'ud, Muhyi al-Sunnah Abu Muhammad al-Husain. (1997). Ma'alim al-Tanzil, jld.

5. Riyadh: Dar Thayyibah li al-Nasyr wa al-Tauz'i

52 Ibnu Katsir, Abul Fida Ismail bin Umar, Tafsir alQur'an al-Azhim, (Berut: Dar al-Thayyibah li alNasyr wa al-Tauzi, 1997), jld. 2, 37.

53 Ibnu Katsir, Tafsir al-Qur'an al-Azhim, ........ jld. 8, 184.
Barnadib, Sutari Imam. (1995). Pengantar Ilmu Pendidikan Sistematis, Yogyakarta: Andi Offset.

al-Mawardi, Abul Hasan Ali bin Habib, (1982). Tafsir al-Mawardi, jld. 4, Kuwait: Mathabi al-Maqhawi.

Ibnu Katsir, Abul Fida Ismail bin Umar. (1997). Tafsir al-Qur'an al-Azhim, jld. 2, Berut: Dar al-Thayyibah li al-Nasyr wa al-Tauzi, 1997

Gufron, Ali. (2013). Tuntutan Berqurban dan Menyembelih Hewan Qurban, Jakarta: Amzah, 2013.

Habib, Mushtafa Rahim Zhahir. (2010). Huquq al-Thifli Baina al- Syari'ah wa alQanun, Riyadh: Wizarah al-Ta'lim al-Ali wa al-Bahts.

Al-Haqil, Sulaiman bin Abdurrahman. (1996). Al-Tarbiyah Al-Islamiyah, Riyadh: Wizaratul 'Ilam.

Al-Jurjani, Ali bin Muhammad bin Ali, AlTa'rifat, (1405). Berut: Dar al-Kitab alArabi

Khalil, Ghassan. (2001). Huquq al-Thifli, Berut: Dar Ibn Katrsir.

Al-Bukhari, Muhammad bin Ismail Abu Abdillah. (1987). Al-Jami Al-Shahih, Berut: Dar Ibn Katsir.

Al-Kailani, Majid Irsan. (1985). Tarhawwur Mafhum Al-Nazhariyah Al-Tarbawiyah Al-Islamiyah, Madinah: Maktabah Dar al-Turats.

Muslim, Abu al-Husain Muslim bin al-Hajjaj. (1430). Al-Jami Al-Shahih, jld. 5, Berut: Dar al-Jil.

Mushthafa, Ibrahim. (1987). Al-Mu'jam AlWasith, jld. 1, Kairo: Dar al-Da'wah, 1987.

Nurul Islam, Muhammad. (2012) . Mafhum Huquq al-Thifli, Berut: Dar Ibn Katsir.

Prints, Darwan. (2003). Hukum Anak Indonesia. Bandung: PT. Citra Aditya Bakti, Bandung.

Al-Qahthani, Said bin Ali bin Wahf. (2011). Al-Hadyu Al-Nabawi fi Tarbiyah Al-Aulad fi Dhaui Al-Kitab wa Al-Sunnah, Riyadh: Muasasah al-Risalah, 2011.

Al-Sa'di, Abdurahman bin Nashir. (2000). Taisir al-Karim al-Rahman fi Tafsir Kalam al-Manan, Berut: Muasasah al-Risalah.

Shadiq, Hisyam Ali, (1986). Tarikh alNuzhum al-Qanuniyah wa al-Ijtima'iyah, Kairo: Matba'ah Jami'ah al-Qahirah.

Al-Asy'ats, Abu Daud Sulaiman. (1426). Sunan Abi Daud, jld 4, Berut: Dar alKitab al-Arabi

Abul Abbas, Syamsudin Muhammad. (1984). Nihayatul Muhtaj ila Syarhil Minhaj, jld. 4, Beirut: Dar al-Fikr. 
Al-Tirmidzi, Muhammad bin Isa Abu Isa. (1427). Al-Jami Al-Shahih Sunan alTirmidzi, jld. 4, Berut: Dar Ihya alTurats al-Arabi.

Thanthawi, Muhammad Sayyid, al-Tafsir alWasith li al-Qur'an al-Karim. (1987), Kairo: Mathba'ah al-Sa'adah.

Ulwan, Abdullah Nasih (1400 H). Tarbiyatul Aulad fi al-Islam, jld. 1, Jedah: Dar Hafizh li al-Nasyr wa ak-Tauzi.
Wafi, Ali Abdul Wahid. (1979). Huquq alInsan fi al-Islam, Kairo, Dar al-Nahdhah Mishr li al-Thab'i wa al-Nashr.

Abdul Baqi, Abu Abdillah Muhammad. (1961). Syarh Muwatha Malik, jld. 3, Kairo: Syirkah wa Maktabah wa Mathba'ah al-Babi al-Halbi wa Auladuhu UU Republik Indonesia Nomot 1 Tahun 1974 tentang Perkawinan. 
Golden Age: Jurnal Pendidikan Anak Usia Dini, Volume 1 Nomor 2 (Desember 2017)

ITAH MIFTAHUL ULUM / Tafsir Hak Ayat dan Relevansinya dengan Pendidikan Anak Usia Dini 